\title{
Synergistic effect of arsenic trioxide, vismodegib and temozolomide on glioblastoma
}

\author{
COSTANSIA BURETA $^{1 *}$, YOSHINOBU SAITOH ${ }^{1}$, HIROTO TOKUMOTO $^{1}$, HIROMI SASAKI $^{1}$, \\ SHINGO MAEDA ${ }^{2}$, SATOSHI NAGANO ${ }^{1}$, SETSURO KOMIYA ${ }^{1}$, \\ NOBORU TANIGUCHI ${ }^{1}$ and TAKAO SETOGUCHI ${ }^{2 *}$
}

\begin{abstract}
Departments of ${ }^{1}$ Orthopaedic Surgery and ${ }^{2}$ Medical Joint Materials, Graduate School of Medical and Dental Sciences, Kagoshima University, Kagoshima 890-8520, Japan
\end{abstract}

Received September 7, 2018; Accepted March 1, 2019

DOI: $10.3892 / o r .2019 .7100$

\begin{abstract}
The treatment of glioblastoma is a critical health issue, owing to its resistance to chemotherapy. The current standard of treatment is surgical resection, followed by adjuvant radiotherapy and temozolomide treatment. Long-term local treatment of glioblastoma is rarely achieved and the majority of the patients undergo relapse. Resistance to temozolomide emerges from numerous signalling pathways that are altered in glioblastoma, including the Hedgehog signalling pathway. Hence, further research is required to identify effective treatment modalities. We investigated the effect of vismodegib, arsenic trioxide and temozolomide on glioblastoma in vitro and in vivo to apply our findings to the clinical setting. WST-1 assay revealed that glioblastoma proliferation was inhibited following treatment with these drugs either in single or in combination; this synergistic effect was confirmed by CalcuSyn software. Western blot analysis revealed an increase in the expression of cleaved caspase-3 and $\gamma \mathrm{H} 2 \mathrm{AX}$. Furthermore, there was marked inhibition and decreased tumour growth in mice that received combination therapy, unlike those that received single agent or vehicle treatment. Our results revealed that the combination of arsenic trioxide/vismodegib and temozolomide may be an attractive therapeutic method for the treatment of glioblastoma.
\end{abstract}

\section{Introduction}

Glioblastomas (GBM, gliomas) are primary brain tumours of glial origin. They are the most common central nervous system

Correspondence to: Dr Takao Setoguchi, Department of Medical Joint Materials, Graduate School of Medical and Dental Sciences, Kagoshima University, 8-35-1 Sakuragaoka, Kagoshima 890-8520, Japan

E-mail: setoro@m2.kufm.kagoshima-u.ac.jp

*Contributed equally

Keywords:glioblastoma,arsenictrioxide,vismodegib,temozolomide, synergism, Hedgehog inhibitor neoplasms in adults. Each year, 5-6 of 100,000 individuals are diagnosed with primary malignant brain tumours, of which $\sim 80 \%$ are malignant gliomas and more than half of these are glioblastomas $(1,2)$. There is a slight male predominance and individuals between 45-70 years of age are mainly affected (3). Despite the aggressiveness in approach which includes surgical resection, irradiation and chemotherapy, GBM is an aggressive neoplasm associated with high mortality resulting from infiltrative growth and recurrence with a uniformly fatal course.

Temozolomide (TMZ) is an alkylating agent used for GBM treatment (4). The approved dosage is $150-200 \mathrm{mg} /$ square metre of body surface area, daily for 5 days of every 28-day cycle. A dosage of $75 \mathrm{mg} / \mathrm{square}$ metre for up to 49 days is safe (5); this extent of exposure to TMZ will damage the DNA repair enzyme encoded in the human as $\mathrm{O}^{6}$-methylguanine-DNA methyltransferase (MGMT) $(4,6)$, but overexpression of MGMT in tumour cells confers resistance to TMZ and impairs therapeutic outcome.

The Hedgehog $(\mathrm{Hh})$ signalling pathway was originally discovered in Drosophila, and regulates embryonic segment development (7). Hh signalling plays a crucial role in GBM tumour progression and pathogenesis. Its activation is mediated by sonic Hedgehog (Shh), which binds to its receptor patched (PTCH) to promote GLI1 activation. Activation of Hh/GLI1 thus promotes the resistance of glioma stem cells to TMZ $(8,9)$.

Arsenic trioxide $\left(\mathrm{As}_{2} \mathrm{O}_{3}\right.$, ATO), a $\mathrm{Hh}$ pathway inhibitor $(10,11)$, is used as a therapeutic agent for acute promyelocytic leukaemia (APL) (12). It has also been reported to show a substantial effect in a wide range of other solid tumours including oesophageal (13), lung (14), liver (15), cervical cancer (16), prostate carcinoma (17) and osteosarcoma (18). Regardless of how sensitive different types of tumour cells are to this drug, there is a limitation in its clinical application in a wide range of haematological malignancies and solid tumours $(19,20)$.

Vismodegib (VIS) is a small molecule inhibitor of smoothened (SMO). In the absence of PTCH1, VIS binds to SMO and inhibits the atypical activation of the Hh pathway (21).

In clinical practice, combination therapy is often used to enhance the cytotoxicity and reduce the adverse effects 
of chemotherapeutic drugs $(19,22)$. In the present study, we demonstrated that the combination of VIS, ATO and TMZ suppressed the growth of GBM.

\section{Materials and methods}

Cell line and reagents. Glioblastoma of unknown origin (GUO) [U-87MG (ATCC ${ }^{\circledR}$ HTB-14 ${ }^{\mathrm{TM}}$ ) (RRID:CVCL_0022)] and U138MG human malignant GBM cell lines were purchased from the American Type Culture Collection (ATCC; Manassas, VA, USA), while U251MG was purchased from the Health Science Research Resource Bank (Osaka, Japan). All cell lines grown as monolayer cultures in minimum essential medium (MEM; Gibco; Thermo Fisher Scientific, Inc., Waltham, MA, USA) were supplemented with $10 \%$ fetal bovine serum (FBS; Gibco; Thermo Fisher Scientific, Inc.) and $1 \%$ penicillin/streptomycin (Gibco; Thermo Fisher Scientific, Inc.) in a humidified atmosphere containing $5 \%$ $\mathrm{CO}_{2}$ at $37^{\circ} \mathrm{C}$.

Temozolomide (TMZ) was purchased from LKT Laboratories Inc. (St. Paul, MN, USA), arsenic trioxide (ATO) was from Nihon Shinyaku Co., Ltd. (Kyoto, Japan) and vismodegib (VIS) was obtained from LC Laboratories (Woburn, MA, USA).

Cell viability assay. Cells were seeded at a density of $10^{3}$ cells/well in 96-well plates and treated with vehicle, 1 or $3 \mu \mathrm{M}$ of ATO, 20 or $50 \mu \mathrm{M}$ of VIS, and 300 or $1,000 \mu \mathrm{M}$ of TMZ. Cell viability was assessed by adding to each well $10 \mu \mathrm{l}$ of a tetrazolium salt (WST-1) (Roche Diagnostics, Basel, Switzerland) which was cleaved by mitochondrial dehydrogenase activity (18). Fluorescence intensity was measured after $2 \mathrm{~h}$ on a microplate reader.

Western blot assay. Briefly, cells were seeded at a density of $10^{5}$ cells/well in 6 -well plates with vehicle, or $1 \mu \mathrm{M}$ ATO, $30 \mu \mathrm{M}$ VIS, or 300 and $600 \mu \mathrm{M}$ TMZ in single or in combination of ATO and TMZ and a combination of VIS and TMZ for $48 \mathrm{~h}$, washed with phosphate-buffered saline (PBS) and lysed using Mammalian Protein Extraction reagent (Thermo Fisher Scientific, Inc.), $3 \mathrm{mM}$ p-APMSF (Wako Chemicals, Kanagawa, Japan) and $5 \mathrm{mg} / \mathrm{ml}$ aprotinin (Sigma-Aldrich; Merck KGaA, Darmstadt, Germany). The lysates were centrifuged at $14,000 \mathrm{x} \mathrm{g}$ for $10 \mathrm{~min}$ at $4^{\circ} \mathrm{C}$. Protein were determined by bicinchoninic acid (BCA) reagents $A$ and $B$ at 50:1. SDS-PAGE (4-15\%) was conducted using $10 \mu \mathrm{g}$ of each protein followed by immunoblotting on polyvinylidene difluoride (PVDF) membrane (Bio-Rad Laboratories, Hercules, CA, USA). Blocking was carried out with $5 \%$ skim milk for $1 \mathrm{~h}$ followed by incubation at $4^{\circ} \mathrm{C}$ with the following antibodies: $\gamma \mathrm{H} 2 \mathrm{AX}$ (cat. no. 2577), H2AX (cat. no. 2595), cleaved caspase-3 (cat. no. 9664) and caspase-3 (cat. no. 9665; all from Cell Signaling Technology Japan K.K., Tokyo, Japan) (23-26) at a dilution of 1:1,000 overnight and alpha-tubulin (cat. no. HRP-66031; ProteinTech Group, Inc., Rosemont, IL, USA) at a dilution of 1:5,000 for $1 \mathrm{~h}$. Incubation at room temperature with horseradish peroxidase-conjugated anti-rabbit secondary antibodies (cat. no. 7074) or anti-mouse (cat. no. 7076) (Cell Signaling Technology Japan K.K., Tokyo, Japan) for $1 \mathrm{~h}$ at a dilution of 1:4,000. Signals were analyzed using ECL Western Blotting reagent (Amersham; GE Healthcare Life Sciences, Little Chalfont, UK) and LAS 4000 Mini image analyzer (Fujifilm, Tokyo, Japan).

Drug combination studies. GUO, U251MG and U138MG cells were seeded in 96-well plates and treated with vehicle, single drug or a fixed drug ratio of the combined drugs. ATO and TMZ was used at 1:320, VIS and TMZ was used at 1:10. Cell viability was assessed by WST-1 assay. The CalcuSyn (version 2.11; Biosoft, Ferguson, MO, USA) median effect model was used to calculate the CI values and to analyse whether the drug combinations were synergistic, antagonistic, or additive. $\mathrm{CI}$ value of $<1$ indicates synergism, $\mathrm{CI}=1$ indicates additivity, and $\mathrm{CI}>1$ indicates antagonism (27).

Animal studies. Four-week-old male nude mice weighing $20 \mathrm{~g}$ (Japan SLC Inc., Hamamatsu, Japan) were used in the present study. Animal care and experimental procedures were specifically approved and carried out in accordance with the guidelines of the Institute of Laboratory Animal Sciences, Graduate School of Medical and Dental Sciences, Kagoshima University (Kagoshima, Japan) (no. MD 17101).

The animals were kept in a pathogen-free environment, with 12-h light/dark cycle at $24^{\circ} \mathrm{C}, 40-70 \%$ relative humidity and a free access to food and water ad libitum. They were allowed to habituate for 7 days prior to tumour inoculation. Briefly, $1 \times 10^{7}$ GUO tumour cells in $50 \mu 1$ MEM lacking FBS and antibiotics combined with $50 \mu 1$ Matrigel (Corning Life Sciences, Tewksbury MA, USA) were inoculated subcutaneously into the flanks of nude mice. Tumours were allowed to grow for 7 days, and then mice were randomly divided into the control and the treatment groups ( $\mathrm{n}=7$ animals/group). They were administered intraperitoneally (i.p) with either TMZ (10 mg/kg/daily), ATO $(2.5 \mu \mathrm{g} / \mathrm{g} /$ daily $)$, or VIS $(25 \mathrm{mg} / \mathrm{kg} /$ day $)$ or in combination of ATO $2.5 \mu \mathrm{g} / \mathrm{g} /$ daily and TMZ $10 \mathrm{mg} / \mathrm{kg} /$ daily or VIS $25 \mathrm{mg} / \mathrm{kg} / \mathrm{daily}$ and TMZ $10 \mathrm{mg} / \mathrm{kg} /$ daily, or with an equal volume of vehicle as the control. These drug concentrations were selected from published studies $(8,14,15,22,28)$, and after conducting a pilot study, we used the minimum effective concentrations so as to be able to apply our results in clinical settings. Injections were given 4 days a week for 2 weeks. Tumour volumes were measured with callipers on alternative days with the longest diameter being the length and the perpendicular diameter being the width; volume was calculated using the formula $\left(\mathrm{Lx} \mathrm{W}^{2}\right) / 2$. The maximum diameter exhibited by a single tumour was $17 \mathrm{~mm}$. Twenty four days after tumour inoculation, animals were sacrificed by inhalation of $\mathrm{CO}_{2}$ at a rate of $10-30 \% / \mathrm{min}$ in an automatic euthanasia plastic chamber. The tumours were excised, weighed, formalin-fixed and paraffin-embedded. Paraffin sections $(4 \mu \mathrm{m})$ were cut and stained with haematoxylin and eosin (H\&E) for light microscopic evaluation.

Statistical analysis. Statistical analyses were carried out using Steel-Dwass test, as a post hoc test for pairwise comparisons following a significant Kruskal-Wallis test with Excel Statistics 2013 (Microsoft Excel; Microsoft Corp., Redmond, WA, USA) and KyPlot 5.0 (KyensLab Inc., Tokyo, Japan). P-values of $<0.05$ were considered to indicate a statistically significant result. 
A

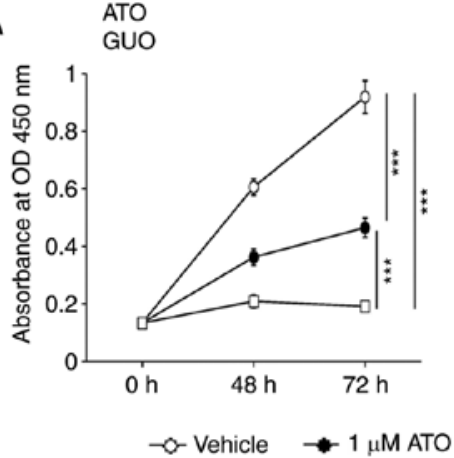

B VIS

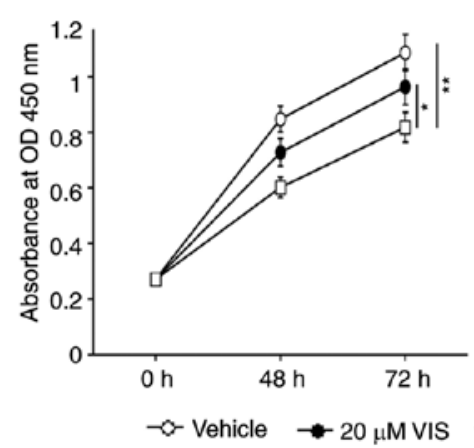

C

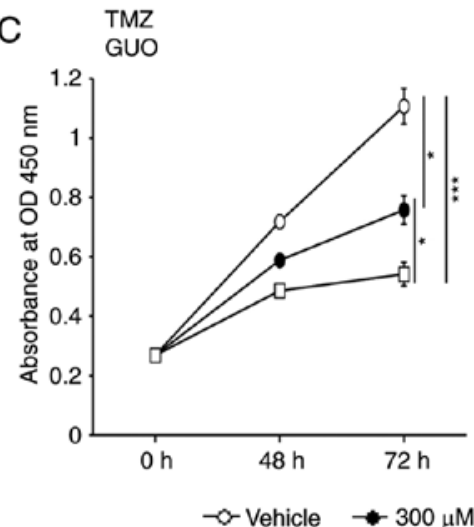

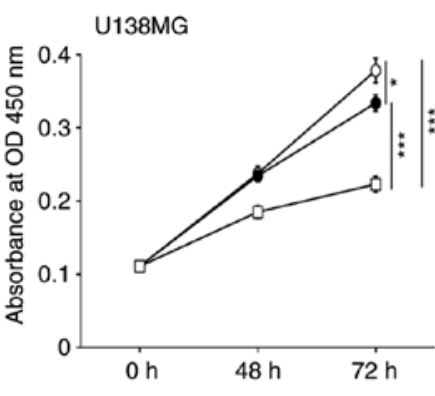

$-\square-3 \mu \mathrm{M}$ ATO
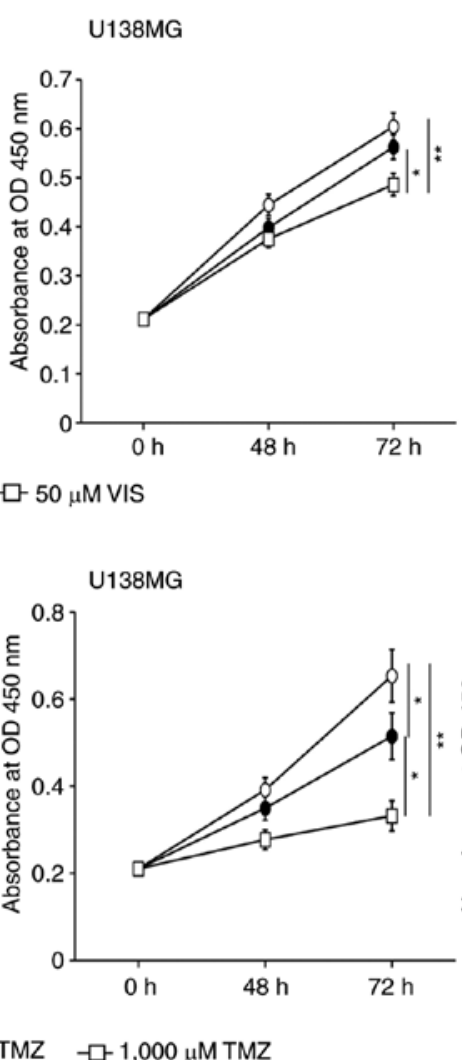
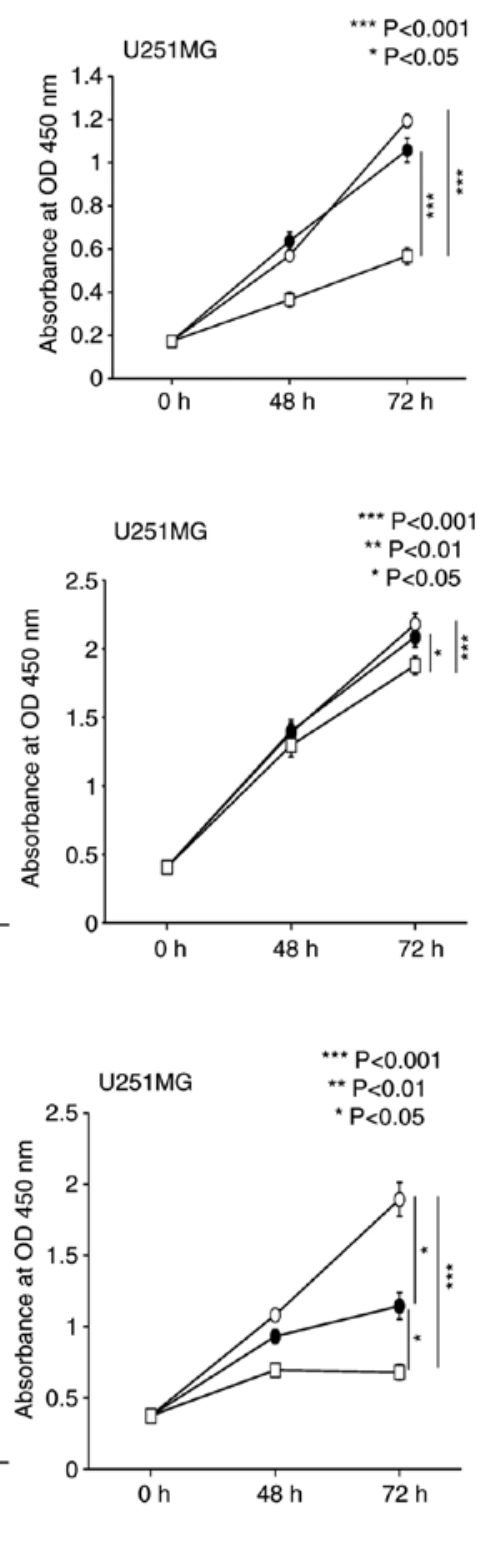

Figure 1. ATO, VIS and TMZ hinder the growth of human GBM cell lines, GUO, U138MG and U251MG. WST-1 assay demonstrated that (A) $1 \mu$ M ATO significantly inhibited the growth of GUO and U138MG cells but did not significantly inhibit the proliferation of U251MG. Yet, $3 \mu \mathrm{M}$ ATO significantly inhibited the proliferation of all the cell lines used. WST-1 assay demonstrated that (B) a concentration of $50 \mu \mathrm{M}$ VIS was significantly more effective in inhibiting the proliferation of the GUO and U138MG and U251MG cells compared to $20 \mu \mathrm{M}$ of VIS which showed only a slight inhibitory effect when compared with the vehicle control. (C) WST-1 assay showed that treatment with 300 and 1,000 $\mu \mathrm{M}$ TMZ significantly inhibited the growth of human GBM cells lines, GUO, U138MG and U251MG cell lines in a dose-dependent manner. The experiment was carried out in triplicate producing similar results. $<<0.05$ was considered significant (Kruskal-Wallis test). Error bars represent the mean \pm SD. ATO, arsenic trioxide; VIS, vismodegib; TMZ, temozolomide; GBM, glioblastoma; GUO, glioblastoma of unknown origin; OD optical density.

\section{Results}

Single-agent efficacy of ATO, VIS and TMZ on the growth of GBM cells. To examine the efficacy of ATO, VIS and TMZ on the growth of GBM cells in vitro, GUO, U138MG and U251MG human GBM cell lines, were used. WST-1 results showed that, there was a dose-dependent inhibition in cell proliferation when all the cell lines were treated with 1 or $3 \mu \mathrm{M}$ of ATO although $1 \mu \mathrm{M}$ ATO did not show significant inhibition in the U251MG cell line (Fig. 1A). A concentration of $50 \mu \mathrm{M}$ VIS was significantly more effective in inhibiting the proliferation of the GUO and U138MG and U251MG cells compared to $20 \mu \mathrm{M}$ of VIS which did not show a significant inhibitory effect when compared with the vehicle control (Fig. 1B). TMZ when used at a concentration of 300 or $1,000 \mu \mathrm{M}$ significantly inhibited the proliferation of GUO, U138MG and U251MG cells (Fig. 1C).

Combination of a Hedgehog $(\mathrm{Hh})$ inhibitor and a standard chemotherapeutic drug hinders the proliferation of GBM cells in vitro. We then examined the effect of treating these cell lines with Hh inhibitors VIS or ATO in combination with TMZ in a dose-dependent manner. Five different concentrations were used at a ratio of 1:320 for ATO:TMZ with the highest concentration being 2:640, and 1:10 for VIS:TMZ with the highest concentration being 64:640 (Table I). When combination 
Table I. Combination index (CI) for a standard anticancer drug when combined with a Hedgehog inhibitor.

\begin{tabular}{llcccccr}
\hline Cell line & \multicolumn{1}{c}{ Drugs } & CI ED $_{50}$ & CI ED $_{75}$ & CI ED $_{90}$ & Dm & $\mathrm{m}$ & $\mathrm{r}$ \\
\hline U87MG & ATO+TMZ (CR 1:320) & 0.91 & 0.70 & 0.56 & 1.53 & 0.82 & 0.99 \\
U138MG & ATO+TMZ (CR 1:320) & 0.63 & 0.67 & 0.78 & 4.4 & 0.53 & 0.98 \\
U251MG & ATO+TMZ (CR 1:320) & 0.49 & 0.59 & 0.93 & 1.1 & 0.69 & 0.98 \\
U87MG & VIS+TMZ (CR 1:10) & 0.5 & 0.4 & 0.35 & 57.49 & 0.82 & 0.96 \\
U138MG & VIS+TMZ (CR 1:10) & 0.53 & 0.54 & 0.57 & 130.66 & 0.79 & 0.96 \\
U251MG & VIS+TMZ (CR 1:10) & 0.28 & 0.19 & 0.15 & 87.84 & 0.98 & 0.94 \\
\hline
\end{tabular}

The CI, Dm and $r$ values were calculated using CalcuSyn software. 'Dm' being the median-effect dose, ' $m$ ' the exponent defining the shape of the dose effect curve and ' $r$ ' indicates the goodness of fit for the data (where $r=1$ is a perfect fit). The $r$ value of the median effect plot for the cell culture system should be $\mathrm{r}>0.95$. $\mathrm{CI}<1$ indicates synergism, 1 indicates additivity and $>1$ indicates antagonism.

A U251MG

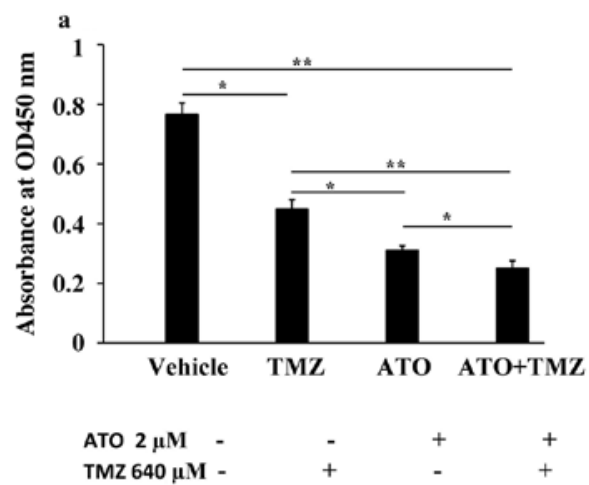

B

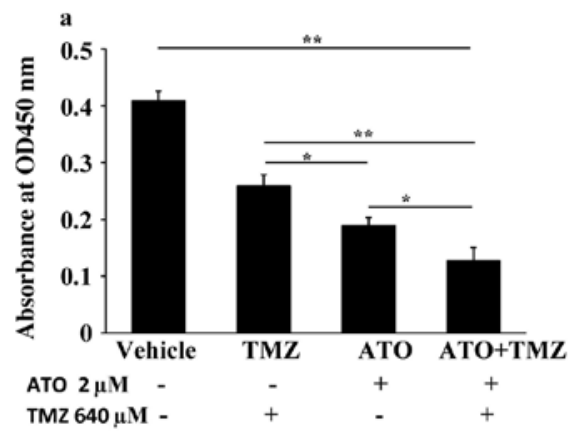

C U138MG

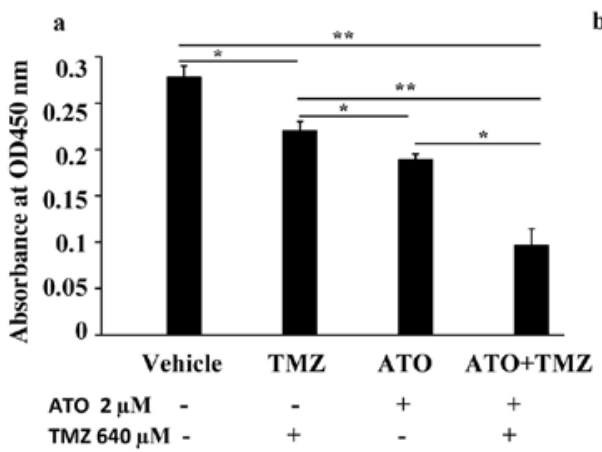

b

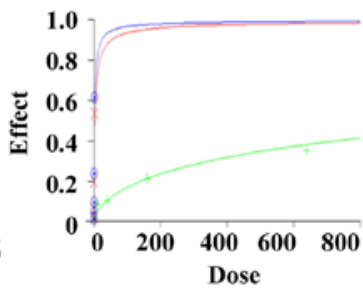

$\times$ ATO + TMZ

• ATO+TMZ
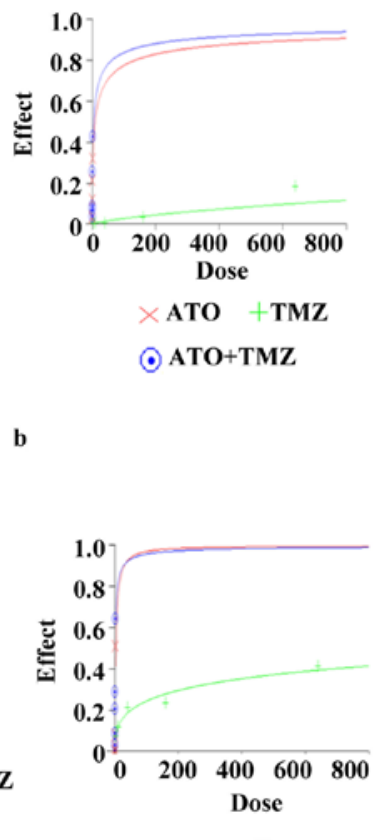

$\times$ ATO + TMZ

(.) ATO+TMZ c

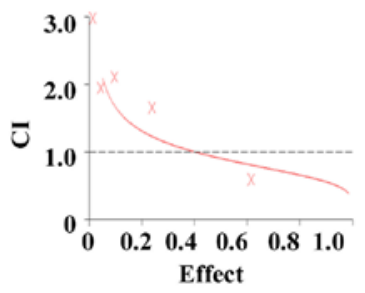

ATO + TMZ $\quad$ CI $=1$

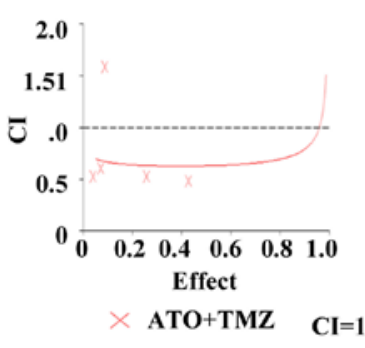

c ** $\mathrm{P}<0.01$

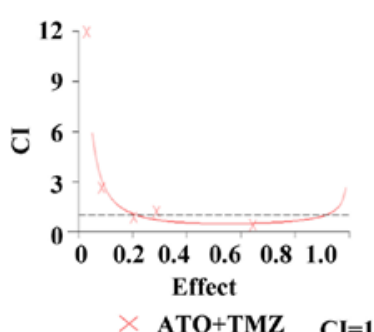

Figure 2. The proliferation of human GBM cells: (A) U251MG, (B) GUO and (C) U138MG cells was inhibited following treatment with a combination of ATO and TMZ. (Aa-Ca) This proliferation effect was analyzed by WST-1 assays. (Ab-Cb) The dose-effect curves of ATO and TMZ in single and in combination are shown. (Ac-Cc) The combination-index and fractions affected were graphed in combination of ATO and TMZ. All the experiments were repeated three times generating similar results. $\mathrm{P}<0.05$, was considered significant (Kruskal-Wallis test). Error bars represent the mean \pm SD. ATO, arsenic trioxide; VIS, vismodegib; TMZ, temozolomide; GBM, glioblastoma; GUO, glioblastoma of unknown origin. CI value of $<1$ indicates synergism, CI=1 indicates additivity, and $\mathrm{CI}>1$ indicates antagonism. 
A
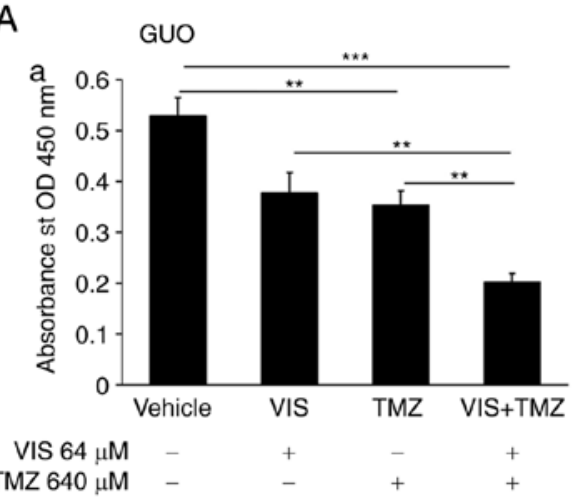

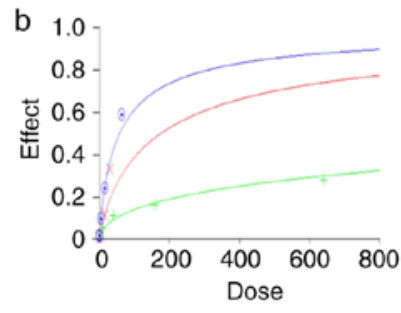

$\times$ VIS + TMZ

(- VIS+TMZ

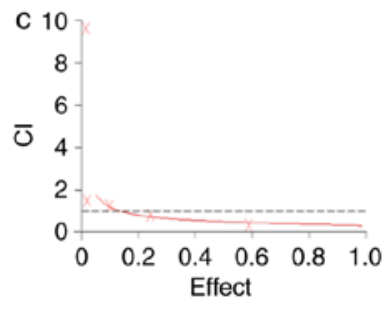

$\times$ VIS + TMZ $\quad \mathrm{Cl}=1$

B

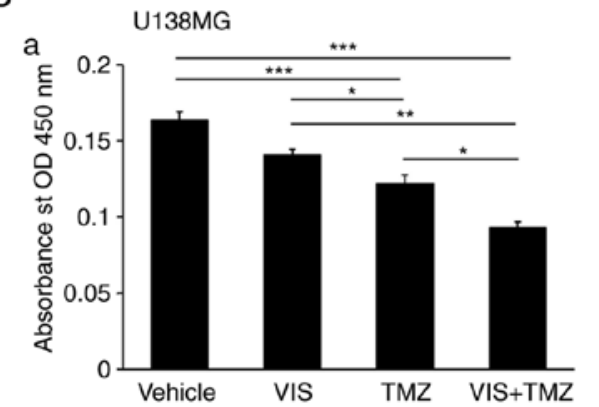

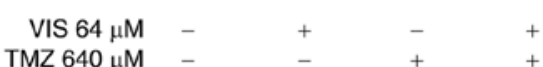
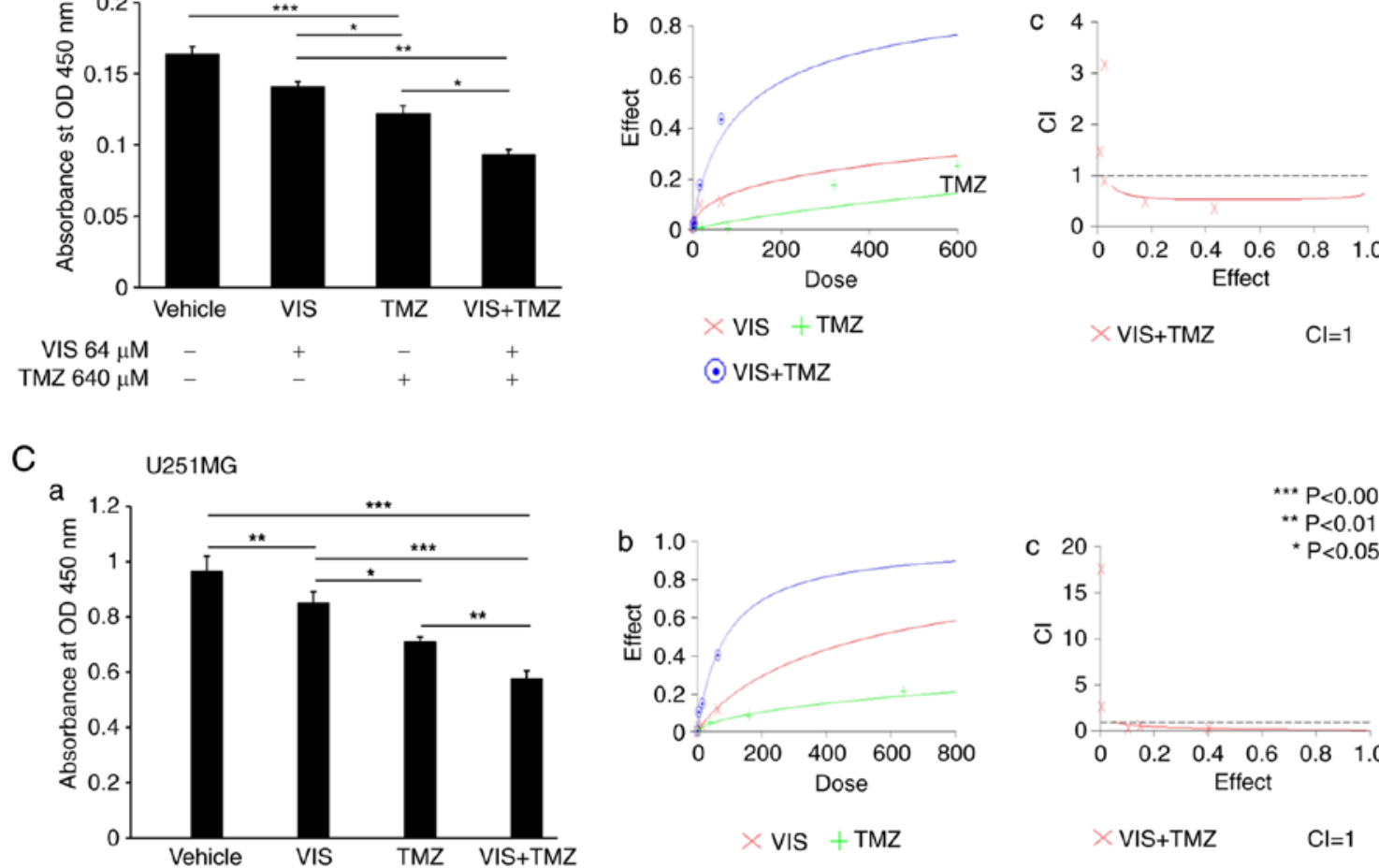

VIS $64 \mu \mathrm{M}$

Vehic

$\begin{array}{ll}T M Z & \text { VIS } \\ - & +\end{array}$

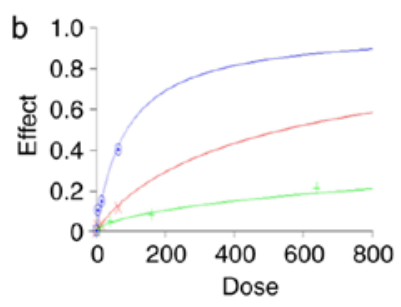

$\times$ VIS + TMZ

(•) VIS $+\mathrm{TMZ}$

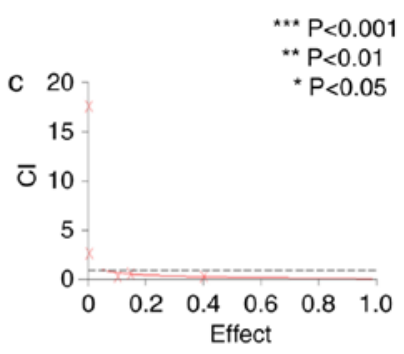

$\times$ VIS + TMZ $\quad \mathrm{Cl}=1$

Figure 3. The proliferation of human GBM cells: (A) GUO, (B) U138MG and (C) U251MG cells was inhibited following treatment with a combination of VIS and TMZ. (Aa-Ca) This proliferation effect was analysed by WST-1 assays. (Ab-Cb) The dose-effect curves of VIS and TMZ in single and in combination are shown. (Ab-Cc) The combination-index and fractions affected were graphed in combination of VIS and TMZ. All the experiments were repeated three times generating similar results. $\mathrm{P}<0.05$ was considered significant (Kruskal-Wallis test). Error bars represent the mean \pm (SD). ATO, arsenic trioxide; VIS, vismodegib; TMZ, temozolomide; GBM, glioblastoma; GUO, glioblastoma of unknown origin. CI value of $<1$ indicates synergism, CI=1 indicates additivity, and $\mathrm{CI}>1$ indicates antagonism.

treatment was used, there was marked inhibition in the proliferation of GBM cell lines, unlike with the use of the single agents. This was shown by assessing the synergistic effect of these drugs by CalcuSyn software version 2.11 (Figs. 2 and 3).

Combination of a Hedgehog (Hh) inhibitor and standard anticancer drug triggered apoptosis of GBM cells in vitro. We next examined the ability of $300 \mu \mathrm{M}$ TMZ when combined with $1 \mu \mathrm{M}$ ATO/30 $\mu \mathrm{M}$ VIS to cause DNA damage and apoptosis in GBM cells following treatment for $48 \mathrm{~h}$. Western blot analyses using $\gamma \mathrm{H} 2 \mathrm{AX}$ and cleaved caspase -3 revealed that there was higher expression of $\gamma \mathrm{H} 2 \mathrm{AX}$ and cleaved caspase- 3 when the drugs were combined, unlike when they were used as single agents (Fig. 4).

Combination of ATO/VIS and TMZ prevents GBM proliferation in vivo. Mouse xenograft models showed that the combination of ATO and TMZ, VIS and TMZ, significantly inhibited GBM proliferation in vivo compared with the vehicle or single drug administration (Fig. 5A and B). We measured the body weight of the mice during the treatments so as to assess the toxicity of these combination treatments. We found that there was no significant difference between the body weights of the control and the treatment groups (Fig. 5C). 
A

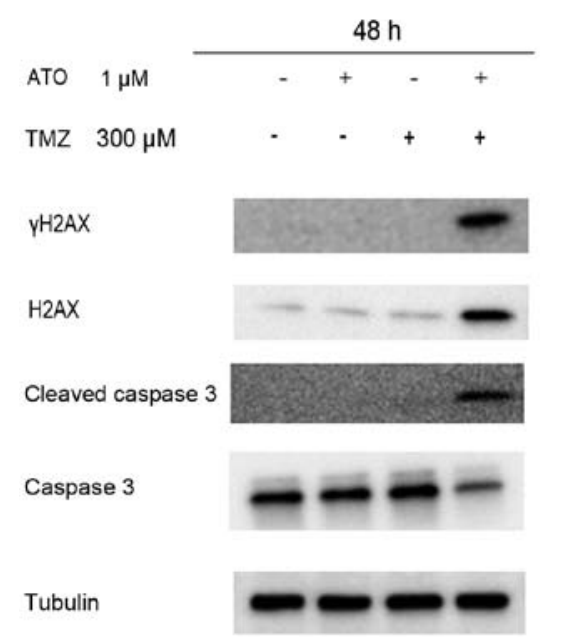

B

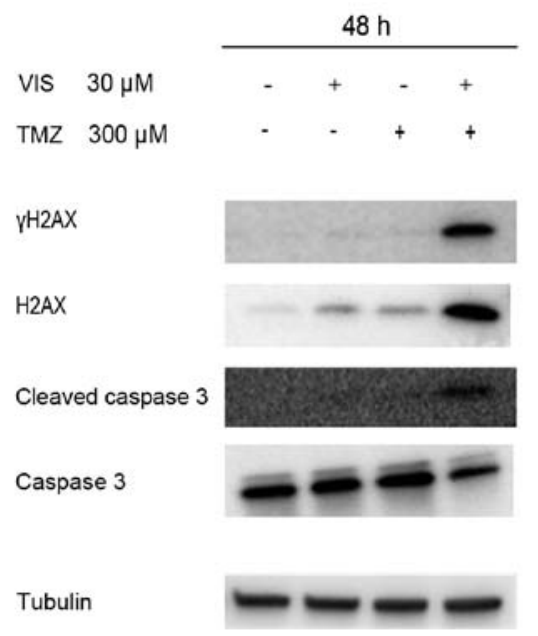

Figure 4. Combination of ATO/VIS and TMZ increased DNA damage and apoptosis, as shown by the increased density of $\gamma \mathrm{H} 2 \mathrm{AX}$ and cleaved caspase-3. ATO, arsenic trioxide; TMZ, temozolomide.

A

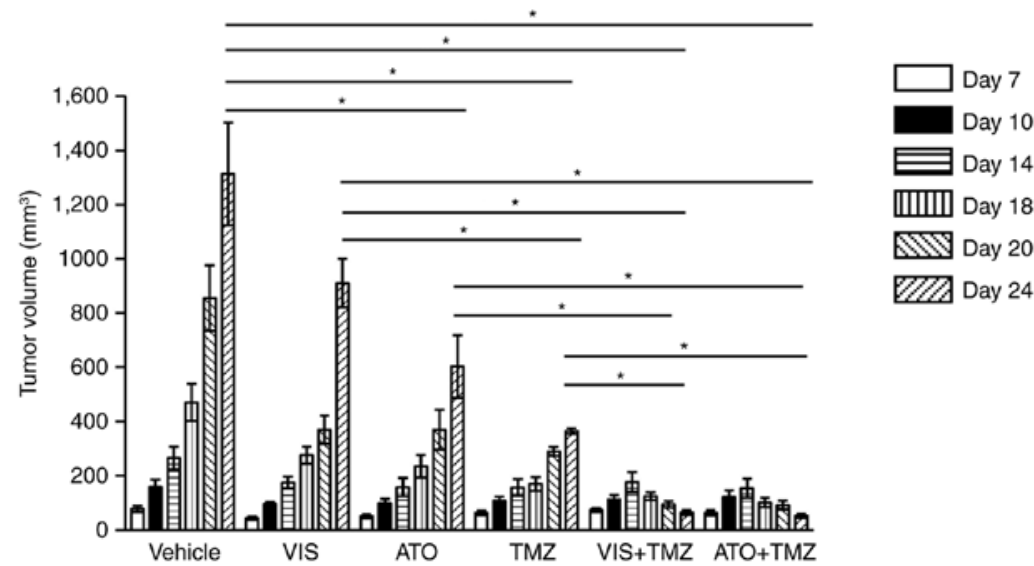

B

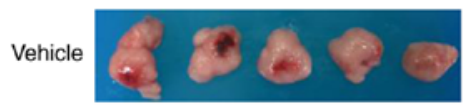

ATO

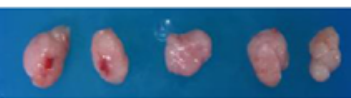

VIS

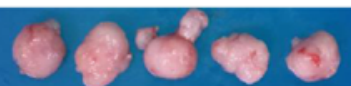

TMZ
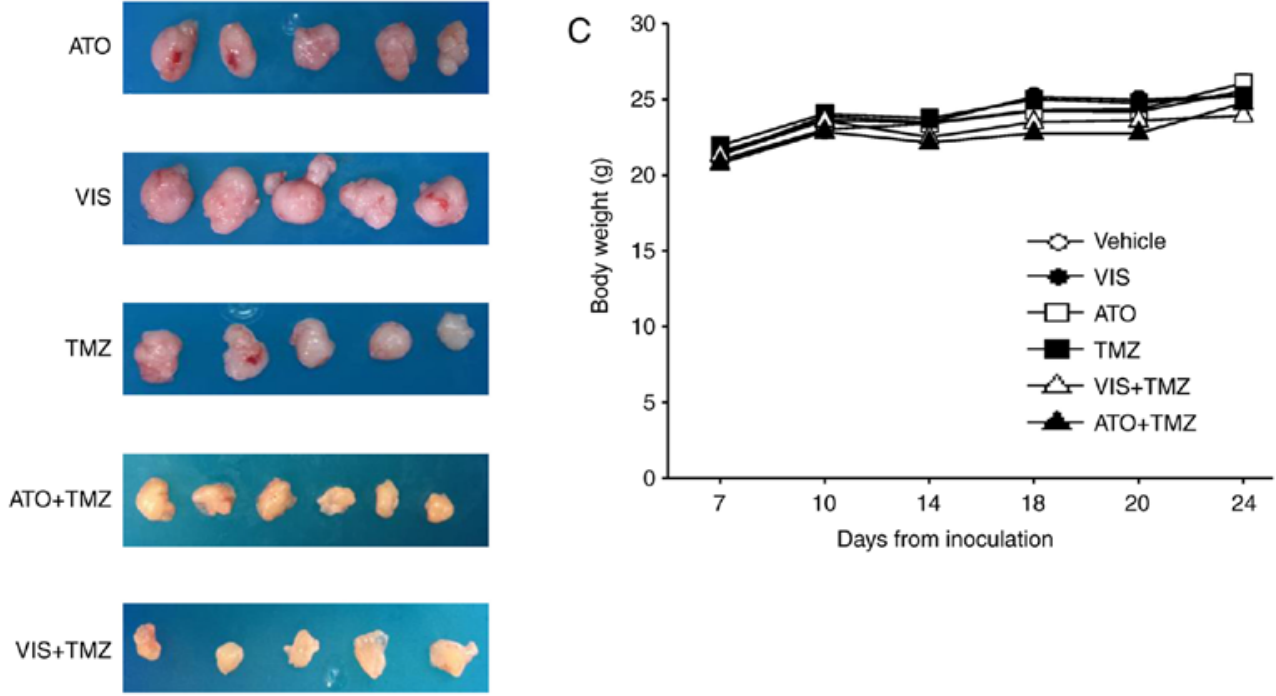

Figure 5. Synergistic chemotherapeutic activity of ATO/VIS and TMZ combination on mouse GUO-derived xenografts. After the establishment of flank tumours, mice were administered i.p. with $2.5 \mu \mathrm{g} / \mathrm{g}$ ATO, $25 \mathrm{mg} / \mathrm{kg} / \mathrm{day}$ VIS and $10 \mathrm{mg} / \mathrm{kg} / \mathrm{day}$ TMZ, or a combination of both regimens for $4 \mathrm{days} / \mathrm{week}$. (A) Tumour volumes $(n=7)$. (B) Representative images of the excised tumours from the mice. $\mathrm{P}<0.05$ was considered significant (Steel-Dwass test). (C) Body weight of mice. ATO, arsenic trioxide; VIS, vismodegib; TMZ, temozolomide; GUO, glioblastoma of unknown origin. 


\section{Discussion}

The emergence of chemotherapeutic drug resistance is a major limitation of therapy for glioblastoma (GBM) patients. In spite of the fact that temozolomide (TMZ) is the standard regimen for GBM, these tumours are highly resistant to chemotherapy (3). On account of the mechanism responsible for such resistance, several factors have been stipulated, and DNA repair-related genes such as $M G M T, M S H 2$ and MSH6 have been recognised as critical factors involved in the survival of the tumour after treatment with alkylating agents (29-31). MGMT expression is also associated with GLI1 activity due to an apparent GLI1-binding site in the MGMT gene promoter (32). Ulasov et al further consolidated the possible link between Hedgehog (Hh) activity and therapeutic resistance to TMZ by their experiments with $\mathrm{CD}_{133^{+}}$glioma stem cells (33).

Arsenic trioxide (ATO) has been approved as an anticancer agent for acute promyelocytic leukaemia (APL) by the Food and Drug Administration (FDA) and Pharmaceutical and Medical Devices Agency (PMDA) in Japan (34). Inhibition of the Hh pathway by ATO could be a useful additional therapy to the standard chemotherapy for GBM. Several mechanisms have been stipulated to account for the inhibition of the $\mathrm{Hh}$ pathway by ATO. In a recent study, ATO was shown to inhibit the transcription of GLI target genes and promote apoptotic cell death in osteosarcoma cells due to increased DNA damage (18). Other authors have also reported inhibition of the expression of GLI2 and downregulation of the expression of SMO and PTCH by ATO $(11,22,35)$. Our findings delineate that ATO hindered the proliferation of GBM cells both in vivo and in vitro.

Vismodegib (VIS) is the first $\mathrm{Hh}$ inhibitor to be approved by the FDA for the treatment of basal cell carcinoma (BCC) $(36,37)$. Smoothened (SMO) inhibitors such as VIS have been evaluated in recent clinical trials (37). Targeting the Hh pathway with VIS blocks aberrant signalling caused by mutational inactivation of the negative regulator PTCH1 or mutational activation of SMO $(37,38)$.

Despite the impressive tumour regression achieved by targeting the Hh pathway with ATO and VIS, resistance has also been reported $(39,40)$ thus, conferring the need for a combination therapy (19).

The combination of ATO (Hh/GLI inhibitor) and alkylating agents has been reported to synergistically inhibit the proliferation of cells with inherited or acquired drug resistance (41). Silencing of GLII in GBM has also been reported to promote sensitivity to TMZ by broadly reducing efflux behaviour attributed to multidrug transporters (42). Our findings revealed that combined treatment with either ATO and TMZ or VIS and TMZ was better at inhibiting GBM growth in vitro and in vivo than single-drug therapy. Among the two combination treatments, a combination of ATO and TMZ has the most promising potential, due to the effectiveness of ATO at a low concentration, compared to VIS. We believe this is the first study to show the synergistic effect of ATO/VIS with TMZ on GBM as determined by the CI-isobologram method of Chou (43) and Chou and Talalay (44).

Other authors including Nagao-Kitamoto et al (22) and Saitoh et al (27) also reported that combined administration of VIS and ATO inhibited Hh pathway activation and tumour growth compared with single-agent therapy. These combinations could reduce the effective concentration of each drug and hence decrease toxicity. In the present study, there was marked inhibition of GBM growth when TMZ was combined with either ATO or VIS.

GBM is a very heterogeneous and genomically unstable tumour $(45,46)$, hence posing the need to identify GBM patients with activated Hh pathway before commencement of treatment with Hh inhibitors. A recent study showed the usefulness of a five-gene $\mathrm{Hh}$ signature that can strongly identify activated $\mathrm{Hh}$ in medulloblastoma (47), and can thus be used for screening patients who have high chances of benefiting from $\mathrm{Hh}$ inhibitor therapies such as GBM patients. There is a high likelihood that the pleiotropic effect of ATO and off-target effects of SMO have a high possibility of affecting the growth inhibition of GBM. However, combination of TMZ with either ATO or VIS showed a promising therapeutic effect for GBM.

In conclusion, these findings denote that a combination of Hh pathway inhibitors and TMZ may be an important and safe therapeutic approach for the treatment of GBM.

\section{Acknowledgements}

We gratefully acknowledge the technical assistance of Hui Gao from the Departments of Orthopaedic Surgery Graduate School of Medical and Dental Sciences, Kagoshima University, Kagoshima, Japan. We are also grateful to the Joint Research Laboratory of Kagoshima University Graduate School of Medical and Dental Sciences.

\section{Funding}

The present study was funded and supported by the Japan's Ministry of Education, Culture, Sports, Science and Technology (scholarship no. 150803).

\section{Availability of data and materials}

All data generated or analysed during this study are included in this published article.

\section{Authors' contributions}

$\mathrm{CB}$ and TS developed the experimental design, conducted the experiments and drafted the manuscript. YS, HT, HS, SM, SN, SK and NT collected, analysed and interpreted the data. All authors read and approved the manuscript and agree to be accountable for all aspects of the research in ensuring that the accuracy or integrity of any part of the work are appropriately investigated and resolved.

\section{Ethics approval and consent to participate}

Animal care and experimental procedures were specifically approved and carried out in accordance with the guidelines of the Institute of Laboratory Animal Sciences, Graduate School of Medical and Dental Sciences, Kagoshima University (Kagoshima, Japan) (no. MD 17101). 


\section{Patient consent for publication}

Not applicable.

\section{Competing interests}

The authors declare that they have no competing interests.

\section{References}

1. Stupp R, Tonn JC, Brada M, Pentheroudakis G and ESMO Guidelines Working Group: High-grade malignant glioma: ESMO clinical practice guidelines for diagnosis, treatment and follow-up. Ann Oncol 21 (Suppl 5): v190-v193, 2010.

2. Schwartzbaum JA, Fisher JL, Aldape KD and Wrensch M: Epidemiology and molecular pathology of glioma. Nat Clin Pract Neurol 2: 494-503, 2006

3. Scorsetti M, Navarria P, Pessina F, Ascolese AM, D'Agostino G, Tomatis S, De Rose F, Villa E, Maggi G, Simonelli M, et al: Multimodality therapy approaches, local and systemic treatment, compared with chemotherapy alone in recurrent glioblastoma. BMC Cancer 15: 486, 2015.

4. Newlands ES, Stevens MF, Wedge SR, Wheelhouse RT and Brock C: Temozolomide: A review of its discovery, chemical properties, pre-clinical development and clinical trials. Cancer Treat Rev 23: 35-61, 1997.

5. Brock CS, Newlands ES, Wedge SR, Bower M, Evans H, Colquhoun I, Roddie M, Glaser M, Brampton $\mathrm{MH}$ and Rustin GJ: Phase I trial of temozolomide using an extended continuous oral schedule. Cancer Res 58: 4363-4367, 1998.

6. Tolcher AW, Gerson SL, Denis L, Geyer C, Hammond LA, Patnaik A, Goetz AD, Schwartz G, Edwards T, Reyderman L, et al Marked inactivation of O6-alkylguanine-DNA alkyltransferase activity with protracted temozolomide schedules. Br J Cancer 88 : 1004-1011, 2003.

7. Amakye D, Jagani $Z$ and Dorsch M: Unraveling the therapeutic potential of the Hedgehog pathway in cancer. Nat Med 19: $1410-1422,2013$

8. Wang K, Chen D, Qian Z, Cui D, Gao L and Lou M: Hedgehog/Glil signaling pathway regulates MGMT expression and chemoresistance to temozolomide in human glioblastoma. Cancer Cell Int 17: 117, 2017.

9. Santoni M, Burattini L, Nabissi M, Morelli MB, Berardi R, Santoni G and Cascinu S: Essential role of Gli proteins in glioblastoma multiforme. Curr Protein Pept Sci 14: 133-140, 2013.

10. Beauchamp EM, Ringer L, Bulut G, Sajwan KP, Hall MD, Lee YC Peaceman D, Özdemirli M, Rodriguez O, Macdonald TJ, et al: Arsenic trioxide inhibits human cancer cell growth and tumor development in mice by blocking Hedgehog/GLI pathway. J Clin Invest 121: 148-160, 2011.

11. Yang D, Cao F, Ye X, Zhao H, Liu X, Li Y, Shi C, Wang H and Zhou J: Arsenic trioxide inhibits the hedgehog pathway which is aberrantly activated in acute promyelocytic leukemia. Acta Haematol 130: 260-267, 2013.

12. Breccia M and Lo-Coco F: Arsenic trioxide for management of acute promyelocytic leukemia: Current evidence on its role in front-line therapy and recurrent disease. Expert Opin Pharmacother 13: 1031-1043, 2012.

13. Yang J, Li H, Chen YY, Wang XJ, Shi GY, Hu QS, Kang XL, Lu Y, Tang XM, Guo QS and Yi J: Anthraquinones sensitize tumor cells to arsenic cytotoxicity in vitro and in vivo via reactive oxygen species-mediated dual regulation of apoptosis. Free Radic Biol Med 37: 2027-2041, 2004.

14. Pettersson HM, Pietras A, Munksgaard Persson M, Karlsson J, Johansson L, Shoshan MC and Påhlman S: Arsenic trioxide is highly cytotoxic to small cell lung carcinoma cells. Mol Cancer Ther 8: 160-170, 2009.

15. Ma Y, Wang J, Liu L, Zhu H, Chen X, Pan S, Sun X and Jiang H: Genistein potentiates the effect of arsenic trioxide against human hepatocellular carcinoma: Role of Akt and nuclear factor- $\mathrm{kB}$ Cancer Lett 301: 75-84, 2011.

16. Yu J, Qian H, Li Y, Wang Y, Zhang X, Liang X, Fu M and Lin C: Arsenic trioxide $\left(\mathrm{As}_{2} \mathrm{O}_{3}\right)$ reduces the invasive and metastatic properties of cervical cancer cells in vitro and in vivo. Gynecol Oncol 106: 400-406, 2007.
17. Maeda H, Hori S, Nishitoh H, Ichijo H, Ogawa O, Kakehi Y and Kakizuka A: Tumor growth inhibition by Arsenic Trioxide $\left(\mathrm{As}_{2} \mathrm{O}_{3}\right)$ in the orthotopic metastasis model of Androgen-independent prostate cancer. Cancer Res 61: 5432-5440, 2001

18. Nakamura S, Nagano S, Nagao H, Ishidou Y, Yokouchi M, Abematsu M, Yamamoto T, Komiya S and Setoguchi T: Arsenic trioxide prevents osteosarcoma growth by inhibition of GLI transcription via DNA damage accumulation. PLoS One 8: e69466, 2013.

19. Subbarayan PR and Ardalan B: In the war against solid tumors arsenic trioxide needs partners. J Gastrointest Cancer 45: 363-371, 2014.

20. Murgo AJ: Clinical trials of arsenic trioxide in hematologic and solid tumors: Overview of the national cancer institute cooperative research and development studies. Oncologist 6 (Suppl 2): S22-S28, 2001.

21. Meiss F and Zeiser R: Vismodegib. Recent Results Cancer Res 201: 405-417, 2014.

22. Nagao-Kitamoto $H$, Nagata $M$, Nagano S, Kitamoto $S$, Ishidou Y, Yamamoto T, Nakamura S, Tsuru A, Abematsu M, Fujimoto Y, et al: GLI2 is a novel therapeutic target for metastasis of osteosarcoma. Int J Cancer 136: 1276-1284, 2015.

23. Mazzucchelli S, Truffi M, Baccarini F, Beretta M, Sorrentino L, Bellini M, Rizzuto MA, Ottria R, Ravelli A, Ciuffreda P, et al: H-Ferritin-nanocaged olaparib: A promising choice for both BRCA-mutated and sporadic triple negative breast cancer. Sci Rep 7: 7505, 2017.

24. Kumar S, Eroglu E, Stokes JA III, Scissum-Gunn K, Saldanha SN, Singh UP, Manne U, Ponnazhagan S and Mishra MK: Resveratrol induces mitochondria-mediated, caspase-independent apoptosis in murine prostate cancer cells. Oncotarget 8: 20895-20908, 2017.

25. Wen W, Zhu F, Zhang J, Keum YS, Zykova T, Yao K, Peng C, Zheng D, Cho YY, Ma WY, et al: MST1 promotes apoptosis through phosphorylation of histone H2AX. J Biol Chem 285: 39108-39116, 2010.

26. Zhu J, Cai Y, Xu K, Ren X, Sun J, Lu S, Chen J and Xu P: Beclin1 overexpression suppresses tumor cell proliferation and survival via an autophagydependent pathway in human synovial sarcoma cells. Oncol Rep 40: 1927-1936, 2018.

27. Saitoh Y, Setoguchi T, Nagata M, Tsuru A, Nakamura S, Nagano S, Ishidou Y, Nagao-Kitamoto H, Yokouchi M, Maeda S, et al: Combination of Hedgehog inhibitors and standard anticancer agents synergistically prevent osteosarcoma growth. Int J Oncol 48: 235-242, 2016.

28. Lin CJ, Lee CC, Shih YL, Lin TY, Wang SH, Lin YF and Shih CM: Resveratrol enhances the therapeutic effect of temozolomide against malignant glioma in vitro and in vivo by inhibiting autophagy. Free Radic Biol Med 52: 377-391, 2012.

29. Hegi ME, Diserens AC, Gorlia T, Hamou MF, de Tribolet N, Weller M, Kros JM, Hainfellner JA, Mason W, Mariani L, et al: MGMT gene silencing and benefit from temozolomide in glioblastoma. N Engl J Med 352: 997-1003, 2005.

30. Dosch J, Christmann M and Kaina B: Mismatch G-T binding activity and MSH2 expression is quantitatively related to sensitivity of cells to methylating agents. Carcinogenesis 19: 567-573, 1998.

31. Yip S, Miao J, Cahill DP, Iafrate AJ, Aldape K, Nutt CL and Louis DN: MSH6 mutations arise in glioblastomas during temozolomide therapy and mediate temozolomide resistance. Clin Cancer Res 15: 4622-4629, 2009.

32. Yoon JW, Gilbertson R, Iannaccone S, Iannaccone $P$ and Walterhouse D: Defining a role for Sonic hedgehog pathway activation in desmoplastic medulloblastoma by identifying GLI1 target genes. Int J Cancer 124: 109-119, 2009.

33. Ulasov IV, Nandi S, Dey M, Sonabend AM and Lesniak MS: Inhibition of sonic hedgehog and notch pathways enhances sensitivity of $\mathrm{CD}_{133}{ }^{+}$glioma stem cells to temozolomide therapy. Mol Med 17: 103-112, 2011.

34. Nasr R, Guillemin MC, Ferhi O, Soilihi H, Peres L, Berthier C, Rousselot P, Robledo-Sarmiento M, Lallemand-Breitenbach V, Gourmel B, et al: Eradication of acute promyelocytic leukemia-initiating cells through PML-RARA degradation. Nat Med 14: 1333-1342, 2008.

35. Kim J, Lee JJ, Kim J, Gardner D and Beachy PA: Arsenic antagonizes the Hedgehog pathway by preventing ciliary accumulation and reducing stability of the Gli2 transcriptional effector. Proc Natl Acad Sci USA 107: 13432-13437, 2010. 
36. SekulicA,Migden MR,OroAE,DirixL,LewisKD,HainsworthJD, Solomon JA, Yoo S, Arron ST, Friedlander PA, et al: Efficacy and safety of vismodegib in advanced basal-cell carcinoma. N Engl J Med 366: 2171-2179, 2012.

37. Gould SE, Low JA, Marsters JC Jr, Robarge K, Rubin LL, de Sauvage FJ, Sutherlin DP, Wong H and Yauch RL: Discovery and preclinical development of vismodegib. Expert Opin Drug Discov 9: 969-984, 2014.

38. Chang AL, Solomon JA, Hainsworth JD, Goldberg L McKenna E, Day BM, Chen DM and Weiss GJ: Expanded access study of patients with advanced basal cell carcinoma treated with the Hedgehog pathway inhibitor, vismodegib. J Am Acad Dermatol 70: 60-69, 2014.

39. Tomita A, Kiyoi $\mathrm{H}$ and Naoe T: Mechanisms of action and resistance to all-trans retinoic acid (ATRA) and arsenic trioxide $\left(\mathrm{As}_{2} \mathrm{O}_{3}\right)$ in acute promyelocytic leukemia. Int $\mathbf{J}$ Hematol 97: 717-725, 2013.

40. Pricl S, Cortelazzi B, Dal Col V, Marson D, Laurini E, Fermeglia M, Licitra L, Pilotti S, Bossi P and Perrone F: Smoothened (SMO) receptor mutations dictate resistance to vismodegib in basal cell carcinoma. Mol Oncol 9: 389-397, 2015.

41. Lee PC, Kakadiya R, Su TL and Lee TC: Combination of bifunctional alkylating agent and arsenic trioxide synergistically suppresses the growth of drug-resistant tumor cells. Neoplasia 12 : 376-387, 2010.
42. Melamed JR, Morgan JT, Ioele SA, Gleghorn JP, Sims-Mourtada J and Day ES: Investigating the role of Hedgehog/GLI1 signaling in glioblastoma cell response to temozolomide. Oncotarget 9: 27000-27015, 2018.

43. Chou TC: Drug Combination studies and their synergy quantification using the chou-talalay method. Cancer Res 70: 440-446, 2010.

44. Chou TC and Talalay P: Quantitative analysis of dose-effect relationships: The combined effects of multiple drugs or enzyme inhibitors. Adv Enzyme Regul 22: 27-55, 1984.

45. Alves TR, Lima FR, Kahn SA, Lobo D, Dubois LG, Soletti R, Borges H and Neto VM: Glioblastoma cells: A heterogeneous and fatal tumor interacting with the parenchyma. Life Sci 89: 532-539, 2011.

46. McDonald K, Joshi S, Jue TR, Yin J and Khasraw M: ATPS-54genomically Unstable Glioblastoma (U-GBM) show exquisite sensitivity to parp inhibition. Neuro Oncol 17: v30, 2015.

47. Shou Y, Robinson DM, Amakye DD, Rose KL, Cho YJ, Ligon KL, Sharp T, Haider AS, Bandaru R, Ando Y, et al: A five-gene hedgehog signature developed as a patient preselection tool for hedgehog inhibitor therapy in medulloblastoma. Clin Cancer Res 21: 585-593, 2015. 